\title{
Educação e Saúde: um Binômio que Merece Ser Resgatado
}

\author{
Health and Education: a Binomial worth \\ being rescued
}

PALAVRAS-CHAVE:

- Educação;

- Saúde;

-Ensino;

-Política;

- Educação Médica.

KEY-WORDS

- Education;

- Health;

- Education, Medical;

- Teaching;

- Politics.

Recebido em: 24/05/2006

Reencaminhado em: 25/01/2007

Aprovado em: 13/02/2007
Carlos Arteaga Rodríguez ${ }^{1}$ Marcelo Garcia Kolling ${ }^{1}$ Peri Mesquida ${ }^{1}$

\begin{abstract}
RESUMO
A especialização tem gerado uma separação entre e educação e saúde, binômio que, na atualidade, se retoma como uma articulação necessária. Daí o objetivo de abordar estas categorias. Realizou-se uma pesquisa teórica para caracterizar a função da educação para o médico e para a saúde. A educação aperfeiçoa no médico sua comunicação, linguagem e autonomia, além de facilitar seu relacionamento humano e contribuir no processo de conscientização das pessoas, resgatando, assim, sua função de educador. Para que as campanhas de promoção e prevenção em saúde tenham êxito, é necessário que a população tenha uma instrução que Ihe permita compreender e participar das mesmas. As escolas precisam incorporar temas como meio ambiente, hábitos tóxicos, sexualidade, planejamento familiar, higiene, exercícios físicos, alimentação, primeiros socorros e trânsito. As faculdades médicas devem oferecer temas de educação que complementem a formação do egresso, e as escolas devem incorporar temas referentes à saúde em busca do bem-estar pleno do cidadão. A educação e a saúde são necessidades sociais que devem ser garantidas pelas instituições governamentais, e o povo, junto ao seu direito de desfrutá-las, tem o dever de contribuir para sua concretização.
\end{abstract}

\begin{abstract}
Specialization has brought about a rupture between health and education, a binomial today being rescued as a necessary combination. The aim of this article is to show the importance of rearticulating these two areas. To this purpose, a bibliographic research was carried out for defining the role education plays for the physician and for health. Education allows the physician to improve his communication skills, language and autonomy. Education turns it easier for him to establish good doctor-patient relationships and increases his ability to provide professional guidance to people. thus returning to him his function as an educator. Education of the population, on the other hand, is a condition for the success of health prevention and promotion campaigns because they depend on the understanding and active participation of the public. Schools need to include health-related subjects such as environment, toxic habits, sex, birth control, hygiene, physical exercise, nutrition, first aid and traffic in their curriculum. Medical schools should offer their students subjects that complement their professional education and the schools should incorporate subjects related to the health and well-being of the population. Education and health are social demands that must be assured by the State. The people are entitled to enjoy these rights but have the duty to contribute to their concretization.
\end{abstract}




\section{INTRODUÇÃO}

Para Melo1, "a educação e a saúde são práticas sociais que sempre estiveram articuladas", tendência que tem sido retomada nas últimas décadas como parte do trabalho do médico e do educador 2,3 .

A Organização Mundial de Saúde (OMS) ${ }^{4}$ definiu a saúde como "estado completo de bem-estar físico, mental e social, e não meramente a ausência de doença". Bem-estar que integra os níveis biológico, psíquico e social, que só poderá ser alcançado quando o indivíduo se formar numa sociedade que lhe permita seu desenvolvimento educacional.

A definição de educação é mais complexa e abrangente. Brandão $^{5}$ entende a educação como um processo de humanização que se dá ao longo de toda a vida, de muitos modos diferentes, ocorrendo em casa, na rua, no trabalho, na igreja, na escola, entre outros. Além de um processo infinito, que acontece em múltiplos espaços e diferentes situações da vida, compreende-se que a educação está ligada à aquisição e articulação do conhecimento popular e científico, entendido como uma reorganização, incorporação e criação do conhecimento ${ }^{6}$.

Compreende-se assim que a saúde e a educação são inseparáveis e interdependentes, pois, para se ter educação, precisa-se da saúde, ao mesmo tempo em que a saúde só é alcançável quando se tem uma boa educação. Ambas, como necessidades sociais, têm um caráter político-social polêmico por serem consideradas direito do povo e dever do Estado, destinadas às grandes massas sem diferenciações. Porém, são privadas e públicas, acarretando diferenças nos princípios de ação.

Este artigo fundamenta-se na reflexão acerca do exercício de uma medicina cada vez mais tecnicista, especializada, fragmentada e curativa, em contraposição à sua essência humana, geral, preventiva e educativa de que necessita a sociedade (2,7-9. $^{2}$. Por sua vez, a educação tem estado à mercê dos avanços técnico-científicos, preocupando-se com a formação do homem para o mercado de trabalho, no caso, competitivo e tecnocrático, mais do que para a vida, isto é, criativo, humano e com uma visão holística do saber10,11. É objetivo do artigo abordar o nexo educação-saúde e apresentar uma perspectiva transformadora da prática médica e educacional.

\section{METODOLOGIA}

Visando caracterizar a função da educação na prática médica e na saúde, realizou-se um ensaio teórico-reflexivo baseado na argumentação e interpretação pessoal ${ }^{12}$. Fez-se um levantamento bibliográfico parcial nas bibliotecas da Universidade Federal do Paraná e da Pontifícia Universidade Católica do Paraná, assim como nas bases de dados Medline e Scie- lo, utilizando como palavras-chave "educação e saúde" e "health and education". O trabalho se apresenta em dois tópicos. $\mathrm{O}$ primeiro discute o papel da educação na formação médica, e o segundo, como a educação pode contribuir para a saúde.

\section{PAPEL DA EDUCAÇÃO NA FORMAÇÃO MÉDICA}

O desenvolvimento do conhecimento humano trouxe consigo o surgimento de inúmeros ramos do saber. A ciência médica percorre um caminho similar, inicialmente representada pela Clínica Geral, e mais tarde por numerosas especialidades médicas. Compreende-se que a especialização médica favorece o distanciamento entre o médico e o paciente, impede a concepção da saúde como um processo global e menospreza o papel do médico como educador ${ }^{13-15}$.

Esta forma de atuação está enraizada nas faculdades médicas e na demanda do mercado de trabalho. Vale assinalar que, na Faculdade de Medicina da Universidade de São Paulo (FMUSP), "a especialização precoce tem sido preocupação constante, e, ainda que $60 \%$ da carga horária sejam dedicados à formação geral do médico, é forçoso reconhecer que a FMUSP é formadora de especialistas"16.

Um exemplo da visão tecnicista e do menosprezo pela prevenção é a existência de uma preocupação maior com o aprendizado de como tratar uma oclusão das artérias coronárias, por meio de complexas técnicas, ao alcance de uma minoria, em lugar de medidas educativas para evitar a aterosclerose, ao alcance da maioria. Além disso, existe uma diferença significativa ao se estimarem custos, riscos e benefícios destas duas ações médicas, tratar versus educar-prevenir. Nesse dualismo da atenção médica, ganha importância a formação educativa e preventiva. Portanto, é responsabilidade da escola médica fazer com que o estudante compreenda o sentido preventivo, educativo e social de sua atividade, visto que foi demonstrado o fracasso da medicina individual, mercantilista e tecnicista ${ }^{17,18}$.

O papel que a educação tem para o desempenho do trabalho médico vai além da prevenção e será analisado atendendo os eixos assistencial, psicológico, ético e de ensino-pesquisa $^{19-22}$.

No eixo assistencial, a educação enriquece a função milenar do médico como educador, promove sua comunicação com os pacientes e equipe de trabalho e facilita conhecer as pessoas segundo o grau de instrução, elementos cardinais para o acompanhamento médico e a adesão terapêutica. A educação para o médico como orientador de condutas éticas é fundamental diante das incertezas e problemas que constantemente enfrenta, com vistas a auxiliar e orientar pacientes e familiares para que possam decidir sobre um procedimento 
no qual eles são leigos, como seria o caso do aconselhamento genético $^{23}$.

No eixo psicológico, a educação permite aprender a ciência e arte da comunicação como requisito para obter uma boa relação médico-paciente (RMP), cultivando a capacidade do médico de persuadir, informar e modificar padrões de conduta, por meio de uma linguagem precisa, utilizando as normas de conduta e de comunicação, além dos valores que medeiam as relações humanas ${ }^{24}$. Vale lembrar que a tecnologia desfavorece o sentido humano da RMP, observação já documentada por Assad25: "A tecnologia tirou o médico da cabeceira de seu paciente, fazendo com que a mão que sentia, tocava, percutia e acariciava fosse substituída por visores luminosos e sonoros, por aparelhagem cada vez mais sofisticada". Tais observações nos permitem destacar o valor do ensino humanístico e ético nas faculdades médicas para reverter essas condutas.

Com relação à psicoterapia não especializada, seguindo as idéias de Balint ${ }^{26}$, "o médico deve aprender a usar-se com a mesma habilidade que o cirurgião demonstra no uso do seu bisturi. Está obrigado a manejar sua própria pessoa com confiança e desenvoltura nas mais difíceis situações". É lógico pensar que este aprendizado só é obtido quando o acadêmico toma consciência desta necessidade, a partir das vivências clínicas com os pacientes. Lembre-se de que o processo de educar-aprender é ativo e bilateral, situação válida no caso do médico e do paciente ${ }^{27}$.

No eixo ético, a educação permite o aperfeiçoamento da ética narrativa, além de cultivar a linguagem, meios e modalidade da comunicação, indispensáveis ao melhor entendimento e compreensão mútua na desigualdade e complexidade da $\mathrm{RMP}^{28,29}$. Além disso, a educação favorece o cumprimento dos princípios éticos e o aperfeiçoamento da disciplina, humildade e autonomia moral. É preciso destacar a existência de médicos brilhantes por seus conhecimentos científicos, mas "analfabetos" no que se refere à comunicação e à relação com pacientes, familiares, alunos e colegas, situação que gera problemas evitáveis.

Em relação ao eixo de ensino-pesquisa, todo médico é um professor e um pesquisador potencial. Daí a importância da educação para desempenhar suas atividades de ensino humanístico e instrutivo, para proferir palestras em congressos e nas atividades de educação sanitária, para aprender a aprender de seus atos, dos pacientes e companheiros de trabalho, para desenvolver seu espírito de superação, auto-exigência e auto-avaliação. No caso do médico professor, a educação é fundamental, pois lhe exige maior competência por parte dos pacientes e maestria pedagógica pelos alunos ${ }^{30}$.
Por sua vez, a massificação da educação médica e a qualidade do ensino que demandam os estudantes na atualidade exigem dos professores domínio dos saberes pedagógicos e didáticos ${ }^{31}$. Tal é a importância destes saberes, que a Didática Especial e a Pedagogia Médica foram disciplinas obrigatórias na pós-graduação sensu stricto FMUSP, tendo tido excelente aceitação pelos próprios alunos ${ }^{32}$. Quanto à investigação, ressalta-se o valor da educação para um cientista na hora da comunicação, escrita ou verbal, dos resultados, de forma precisa, compreensiva, didática e ética, além de resguardar os princípios humanos e éticos que devem caracterizar as pesquisas médicas ${ }^{33}$.

\section{PAPEL DA EDUCAÇÃO PARA A SAÚDE}

Considera-se que, para alcançar a meta de Saúde para Todos ${ }^{34,35}$, não basta desenvolver a atenção primária, mas também uma educação voltada às necessidades e possibilidades da comunidade. A prática médica contemporânea reconhece que, para melhorar o panorama da Saúde Pública, é necessário educar as grandes massas, com o objetivo de promover campanhas em prol da saúde e em detrimento das doenças tributárias de prevenção e controle por meio de medidas educativas e sanitárias, como a eliminação de mosquitos, desratização, beber água potável, mudar hábitos higiênico-dietéticos e realizar sistematicamente exercícios físicos, entre outras.

Para cumprir essa missão, sanitária e educativa, é imprescindível que o povo tenha uma instrução que lhe permita aprender as medidas indicadas e tomar consciência do cumprimento e divulgação das mesmas, assim como contar com essa informação através dos meios de comunicação e na escola.

No início do século 20, na cidade de Rio de Janeiro, a renovação da urbe foi acompanhada por uma campanha de saúde encabeçada pelo notável médico Osvaldo Cruz, a qual tinha como objetivos principais erradicar o mosquito Aedes aegypti, transmissor da febre amarela, e a vacinação contra a varíola. Nessa época, trabalhos pioneiros para educar o público foram desenvolvidos pelo dr. Carlos Chagas, que ajudou a eliminar a malária e descobriu o vetor e agente da doença que leva seu nome, a Doença de Chagas ${ }^{36,37}$.

No Brasil, as primeiras campanhas de educação destinadas às grandes massas remontam aos anos de 1940-50, representadas pela Campanha Nacional de Educação de Adolescentes e Adultos (CEAA) e a Campanha Nacional de Educação Rural (CNER). Estas campanhas se destinavam alfabetizar grandes contingentes, a difundir a educação de base no meio rural, a levar aos indivíduos e às comunidades os conhecimentos teóricos e técnicos indispensáveis a um nível de vida 
compatível com a dignidade humana e as idéias da democratização. É interessante destacar que por essa data os órgãos centrais da Educação e Saúde do Brasil estavam integrados em um só organismo de direção central: O Ministério de Educação e Saúde ${ }^{38}$ - situação que expressava a necessidade, ainda vigente, da integração do trabalho da educação e da saúde em todos os níveis.

Com o respaldo da CNER, aparecem mais tarde inúmeras instituições no Brasil sob a orientação da Igreja Católica e do Serviço Social, entre elas as Missões Rurais de Educação (1951 até 1963), pautadas nas experiências das Missões do México, integradas por uma equipe interdisciplinar (agrônomos, médicos, assistentes sociais e agentes de economia doméstica). Estas percorriam as cidades do interior com o objetivo de ministrar ensinamentos sobre higiene, alimentação, técnicas agrícolas, enfermagem, trabalhos manuais e outros ${ }^{39}$.

O valor histórico destas campanhas surgidas no chamado “Período de Otimismo Pedagógico Brasileiro" reside em seu propósito de combater o analfabetismo e melhorar o nível de vida, sobretudo do homem do campo, catalogado como um setor disfuncional dentro do Estado Brasileiro. Naquele momento, o ministro da Educação ${ }^{40}$, referindo-se ao homem do campo, comentou: "vegeta à margem da civilização e sanitariamente é um perigo coletivo, pois tende a fixar e propagar os focos endêmicos", considerações que ainda se expressam no analfabetismo e na marginalidade que favorecem o descontrole das doenças transmissíveis e impedem a implementação das normas de higiene individuais e coletivas. Compreende-se, assim, o grau de interdependência das categorias educação e saúde e as dificuldades de promover saúde sem educação.

Segundo Vasconcelos ${ }^{41}$ na década de 1970 consolidou-se a participação popular na dinâmica de funcionamento dos serviços de saúde, em que se destaca o projeto de saúde da região de Montes Claros, no norte de Minas Gerais, iniciado em 1974, o qual procurava a participação da comunidade sob a orientação dos trabalhadores da saúde. Para esse autor, nessa década existia a forte crença de que os serviços de saúde seriam beneficiados pela idéia hegemônica da "Pedagogia Libertadora" comprometida com a transformação social. Desde as décadas de 1970 e 1980, houve um crescimento dos movimentos populares, reconhecidos pelo Estado brasileiro como interlocutores legítimos, tendo sua máxima expressão nos Conselhos Municipais de Saúde ${ }^{41}$.

Julga-se que, para dar cumprimento a estes objetivos, a escola continua tendo um papel preponderante, mas não exclusivo, pois também deverão estar envolvidas na responsabilidade da educação sanitária o professor, a família e a socie- dade, e, dentro desta, o médico e a equipe de saúde - de forma que estes elementos se integrem com uma concepção colegiada para garantir a formação do homem preconizado para o século 21 pela Organização das Nações Unidas para a Educação e Desenvolvimento ${ }^{42}$.

Dentro dos múltiplos tópicos incluídos nos chamados temas transversais, compete à escola ensinar temas referentes a educação ambiental, sexualidade, ética, cidadania, trânsito e paz com o objetivo de elevar a moral cívica e a convivência multicultural. Para Busquets et al. ${ }^{3}$, os objetivos da educação para a saúde na escola são: formar uma personalidade autônoma, capaz de construir seu próprio estilo de vida e conseguir um equilíbrio que lhe proporcione bem-estar no terreno físico, psíquico e social; oferecer os meios para que o aluno se conscientize de seus próprios estados físicos e psíquicos, dos hábitos e atitudes diante das diversas situações da vida cotidiana. Na Espanha, estas matérias constituem o centro das atuais preocupações sociais, devendo ser o eixo em torno do qual deve girar - como numa espiral - a temática das matérias curriculares reconhecidas como de eixos longitudinais ${ }^{43}$.

No Brasil, o Ministério da Educação e Cultura (MEC) promove desde 1995 um debate nacional com vistas à formulação de novos parâmetros curriculares em nível nacional, que incluem ética, pluralidade cultural, meio ambiente, saúde e orientação sexual, temas para serem trabalhados nas escolas de forma transversal aos conteúdos tradicionais no Ensino Fundamental e Secundário ${ }^{44}$. Nós consideramos que os temas transversais deveriam abarcar todos os níveis de ensino, sendo o conteúdo e a complexidade dos mesmos determinados pelos órgãos e pessoas responsáveis, oferecendo os conteúdos de forma gradual e progressiva. Tais mudanças da estrutura curricular clássica para conteúdos mais amplos estão dadas pela necessidade do momento histórico, em que a concepção holística e a globalização do mundo impõem novas metas ao sistema educacional.

Desta análise, propõe-se que o currículo da educação para a saúde contenha os seguintes temas:

1) Higiene pessoal e coletiva: tomar banho; lavar as mãos antes das refeições e após ir ao banheiro; uso correto das latrinas sanitárias; não roer as unhas; higiene bucal; limpeza da casa e da comunidade; evitar o uso dos utensílios pessoais de forma coletiva; realizar atividades de esporte e lazer; proteger o meio ambiente e os recursos materiais de uso público;

2) Educação médica e sanitária: importância da vacinação; armazenamento e descarte de remédios; perigos da automedicação; imprescindibilidade da visita periódica ao médico e ao dentista; medidas para prevenir e evitar 
a transmissão de enfermidades infectocontagiosas; orientações sobre a dieta, exercícios físicos e hábitos tóxicos; como evitar os acidentes domésticos, de trânsito e de trabalho; conhecimentos básicos acerca dos primeiros socorros e como procurar os serviços emergenciais;

3) Orientações sobre o organismo e suas funções: como preservar o bom desempenho fisiológico do organismo; autonomia moral e intelectual; como manejar o estresse para evitar a fadiga e depressão; como evitar as lesões por esforço repetitivo; orientações sobre a digestão dos alimentos e higiene do sono; como praticar sexo seguro e como utilizar os métodos anticoncepcionais;

4) Pautas de convivência: conduta ética e padrões de comportamento cívico; convivência familiar e social; como lidar com problemas cotidianos e evitar a violência; como compartilhar a vida no coletivo de forma solidária; não dirigir em estado de embriaguez e respeitar os sinais do trânsito; exaltação dos sentimentos humanos; amor pelos valores pátrios e cultura nacional.

Seria responsabilidade dos órgãos do Estado, instituições, escolas, professores e profissionais de saúde, num trabalho conjunto e integrado desde o nível central até a base, estabelecer qual conhecimento e a melhor forma de oferecê-lo, levando em conta o grau de informação e nível escolar das pessoas para as quais é dirigido, assim como sua maneira de pensar, de produzir e de perceber o mundo, em particular das chamadas classes subalternas, misturando de forma criativa o conhecimento comum com o científico de tal modo que se enriqueçam mutuamente ${ }^{15,45-47}$. Utilizariam, para isso, os recursos humanos, didáticos, da comunicação e técnicos disponíveis, envolvendo a família, a escola, a comunidade e a nação na missão de educar o homem para a vida.

No Brasil, é um mérito do Ministério da Saúde ter proibido a publicidade televisiva encaminhada a estimular o hábito de fumar - apesar da resistência dos grandes consórcios como parte da campanha nacional contra o fumo, exemplo a ser seguido por outros países. Pena que este meio de comunicação, acessível à maioria do povo, não tenha maior utilidade para os fins da educação e promoção da saúde, em contraposição à excessiva violência, desrespeito à velocidade no uso do automóvel, propaganda a favor da ingestão do álcool e uso de remédios de efeitos "milagrosos".

Outro aspecto extremamente contraditório e também não menos importante são as possibilidades reais da população para cumprir as orientações de higiene. $\mathrm{O}$ povo pode estar convencido da necessidade de lavar as mãos, ter uma dieta balanceada, fazer exercícios físicos e estudar. Mas onde estão a água, a alimentação elementar, o ginásio de esportes, as escolas com seus professores para esse povo que sente como sua a necessidade de viver saudável e educado? Consideramos o Estado e os órgãos do Governo, junto a suas dependências de direção, administração e de serviços, como os principais responsáveis por garantir ou facilitar a aquisição desses recursos básicos. Vale lembrar que tal situação de impotência ante o necessário e vital é um fator que engendra a passividade, a ociosidade e os atos delitivos.

\section{COMENTÁRIO FINAL}

A marginalidade e as epidemias são sombras do mesmo mal - a falta de educação e saúde. O médico e o professor têm o dever de colaborar para a superação cultural, educacional e sanitária da sociedade. Mas esta articulação milenar, educação e saúde, tem sido afetada pelo desenvolvimento técnico-científico.

A função do médico como educador deixou de ter importância dentro da classe médica, que valoriza mais a especialização e o tecnicismo, mostrando maior interesse pelos aspectos individuais e curativos do que pelos aspectos comunitários, preventivos e educativos necessários à sociedade. Além disso, o médico precisa da educação para cumprir com êxito suas funções assistenciais e de ensino-pesquisa.

Por sua vez, a educação renegou suas funções em prol da saúde, que vão desde a orientação para evitar a cárie dental até como prevenir a síndrome da imunodeficiência adquirida.

Daí que as faculdades médicas devem oferecer temas de educação que complementem o trabalho médico, e as escolas devem incorporar temas referentes à saúde na procura do bem-estar pleno do cidadão.

Em fim, compreende-se que a educação e a saúde são necessidades sociais, que devem ser garantidas pelas instituições governamentais, e o povo, junto ao seu direito de desfrutá-las, tem o dever de contribuir para sua concretização.

\section{REFERÊNCIAS}

1. Melo JAC. Educação Sanitária: uma visão crítica. Cadernos do CEDES/ Educação em Saúde. 1987; 4:28-43.

2. Engel G. The need for a new medical model: A challenge for biomedicine. Science 1977; 196: 129-136.

3. Busquets MD, Leal A. A educação para a saúde. In: Busquets MD, Cainzos M, Fernández T, Leal A, Moreno M, Sastre G. Temas transversais em Educação: Bases para uma formação integral. São Paulo: Ática; 1998. p. 61-103. 
4. Organização Mundial da Saúde. Constituição da Organização Mundial para a Saúde. In:Conferência Internacional da Saúde 19-22 julho de 1946. New York: OMS;1946.

5. Brandão CR. Educação? Educações: aprender com o Índio. In: Brandão CR. O que é educação. 33aㅗ ed. São Paulo: Brasiliense; 1995. p. 7-12.

6. Gadotti M. Advertência final-pensamento pedagógico brasileiro: unidade e diversidade. In: Gadotti M. Pensamento Pedagógico Brasileiro. São Paulo: Ática; 1990. p. 130-139.

7. Capra F. A influência do pensamento cartesianonewtoniano: a concepção mecanicista da vida. In: Capra F. O ponto de mutação: a ciência, a sociedade e a cultura emergente. São Paulo: Cultrix; 1982. p. 95-115.

8. Aguiar AC. Tendências na educação médica: um modelo curricular ajustado ao conceito ampliado de saúde, às mudanças tecnológicas e à realidade social. In: Arruda BKG, org. A educação profissional em saúde e a realidade social. Recife: IMIP/ Ministério da Saúde; 2001. p. 69-86.

9. Cordeiro, H. A escola médica e o novo modelo de cuidados de saúde do SUS: Saúde da Família. In: Arruda BKG, org. A educação profissional em saúde e a realidade social. Recife: IMIP/ Ministério da Saúde; 2001. p. 87-120.

10. Dellors J. Educação: um tesouro a descobrir: relatório para a UNESCO da Comissão Internacional sobre Educação para o Século XXI. São Paulo: Cortez; 1999.

11. Behrens MA. O Paradigma Emergente e a Prática Pedagógica. Curitiba: Champagnat; 2000.

12. Severino AJ. Metodologia do trabalho científico. São Paulo: Cortez;2000.

13. Lopes OC. A Medicina no Tempo. São Paulo: Melhoramentos;1970.

14. Ferreira J R. Ciências da Saúde. Rev. Bras. Educ. Med. 1998; 22: 5-8.

15. Santos BS. Um discurso sobre as Ciências. Porto: Afrontamento; 2001.

16. Vieira JE, Lopes Jr A, Basile MA, Martins MA. Identificação das Diretrizes Curriculares Nacionais do Curso de Graduação em Medicina pelos alunos da Universidade da São Paulo. Rev. Bras. Educ. Med. 2003; 27: 96-103.

17. Venturelli J. Nuevas experiencias educacionales en las ciencias de la salud. In: Venturelli J. Educaçión Médica: Nuevos enfoques, metas y métodos. Washington: OPS; 1997.p. 206-234.

18. Almeida MJ. A Educação Médica e as atuais propostas de mudanças: alguns antecedentes históricos. Rev. Brás. Educ. Méd. 2001; 25: 42-52.
19. Silva PCT. Assessoria Pedagógica. Rev. Bras. Educ. Med. 1982; 6: 7-8.

20. González MR. Algunos aspectos psicológicos de la divulgación sanitaria In: González MR. Psicología para Médicos Generales.Ciudad de la Habana: Científico-Técnica; 1984. p. 25-29.

21. Gonçalves EL. Os objetivos da educação médica. Rev. Bras. Educ. Med. 1998; 22: 9-18.

22. Shapiro I. Doctor means teacher. Acad Méd. 2001; 76: 711.

23. Mackay CR. The effects of uncertainty on the physicianpatient relationship in predictive genetic testing. J Clin Ethics. 1991; 2: 247-250.

24. Boulos M. Relação Médico-Paciente: o ponto de vista do clinico. In: Marcondes E, Gonçalves EL. Educação Médica. São Paulo: Sarvier;1998. p. 50-57.

25. Assad JE. Relação médico-paciente no final do século XX. In: Desafios éticos. Brasília: Conselho Federal de Medicina; 1993. p.104-111.

26. Balint M. Psicoterapia pelo clínico geral. In: Balint M. O médico, seu paciente e a doença. Rio de Janeiro - São Paulo: Atheneu, 1984. p. 233-245.

27. Ramos CL, Melo JAC, Soares JCRS. Quem educa quem? Repensando a relação médico-paciente. In: Costa NR, Ramos CL, Minayo MCS, Stotz EM, org. Demandas populares, políticas públicas e saúde. v. II. Petrópolis: Vozes; 1989. p. 145-161.

28. Brody H. The four principles and narrative ethics. In: Gillon $\mathrm{R}$, org. Principles of biomedical ethics. Chichester, UK: John Wiley \& Sons;1994.

29. Schramm FR. Contribuições da bioética e da comunicação à educação médica. Rev. Bras. Educ. Med, 2001; 25: 15-24.

30. Batista NA, Silva SHS. A função docente em medicina e a formação/educação permanente do professor. Rev. Bras. Educ. Med. 1998; 22:31-36.

31. Rodríguez CA. As inovações no ensino superior e a formação do médico professor [dissertação] Curitiba: Pontifícia Universidade Católica do Paraná; 2003.

32. Marcondes E, Gonçalves EL. Educação Médica. São Paulo: Sarvier; 1998.

33. Costa SIF, Garrafa V, Oselka G, org. Iniciação à bioética. Brasília: Conselho Federal de Medicina;1998.

34. Organização Mundial da Saúde. Saúde para todos.[Washington]:OMS;1997. Disponível em: <http:/ / www.who.int/about who/en/ healthforall.htm> [Acessado em: 16/01/2004]. 
35. Campos FE, Ferreira JR, Feuerwerker L, Sena RR, Campos JJB, Cordeiro H, Cordoni Jr L. Caminhos para aproximar a formação de profissionais de saúde das necessidades da Atenção Básica. Rev. Bras. Educ. Med. 2001; 25:53-59.

36. Skidmore TE. A criação do Brasil "Moderno": 1870-1910. In: Skidmore TE. Uma História do Brasil. São Paulo: Paz e Terra; 1998. p. 97-135.

37. Punukollu G, Gowda RM, Khan IA. Early twentieth century descriptions of the Chagas heart disease. Int J Cardiol, 2004; 95: 347-349.

38. Ammann SB. Desenvolvimento de comunidade no meio rural. In: Ammann SB. Ideologia do desenvolvimento da Comunidade no Brasil. 9a ed. São Paulo: Cortez;1980. p. 47-56.

39. Ammann SB. Ideologia do desenvolvimento da Comunidade no Brasil. São Paulo: Cortez, 1980.

40. Brasil. Ministério de Educação e Cultura. Educação Rural. Discurso pronunciado pelo Ministro Clovis Salgado Filho, em Rosário, Minas Gerais. Revista da CNER 1958; (5):13-1-57.

41. Vasconcelos EM. Os movimentos sociais no setor da saúde: um esvaziamento ou uma nova configuração? In: Valla VV. org. Saúde e Educação. Rio de Janeiro: DP\&A; 2000. p. 33-59.

42. Suhr MW. Abertura de espírito para uma vida melhor. In: DELLORS, J. Educação: um tesouro a descobrir. São Paulo: Cortez; 1999. p. 252-256.
43. Busquets MD, Cainzos M, Fernández T, Leal A, Moreno M, Sastre G. Temas transversais em Educação: Bases para uma formação integral. São Paulo: Ática;1998.

44. Araújo UF. Apresentação à Edição Brasileira. In: Busquets MD, Cainzos M, Fernández T, Leal A, Moreno M, Sastre G. Temas transversais em Educação: Bases para uma formação integral. São Paulo: Ática; 1998. p. 9-17.

45. Valla VV. A crise de interpretação é nossa: procurando compreender a fala das classes subalternas. Revista Educação e Realidade.1996; 21: 117-190.

46. Fonseca LCS. Ensino de Ciências e Saber Popular. In: Valla VV, org. Saúde e Educação. Rio de Janeiro: D P\& A: 2000. p. 87-104.

47. Peregrino M. Uma questão de saúde: saber escolar e popular nas entranhas da escola. In: Valla VV, org. Saúde e Educação. Rio de Janeiro: DP\&A; 2000. p. 61-85.

\section{Conflito de Interesse}

Declarou não haver.

\section{Endereço para correspondência}

Carlos Arteaga Rodríguez

Rua Oyapock, 367 - Cristo Rei

80050-450 - Curitiba - Paraná

e-mail: arteaga.carlos@pucpr.br 